\title{
Improving Supply Chain Management in an Integrated Planning Centre
}

\author{
Arkadiusz KOWALSKI ${ }^{1}$, Krzysztof MONASTYRSKI ${ }^{1}$, Václav ZUBR ${ }^{2}$ \\ ${ }^{1}$ Wroclaw University of Science and Technology, Wroclaw, Poland \\ arkadiusz.kowalski@pwr.edu.pl \\ ${ }^{2}$ University of Hradec Kralove, Hradec Kralove, Czech Republic \\ vaclav.zubr@uhk.cz
}

\begin{abstract}
Currently supply chain management in a large company is an extremely complex undertaking. In order to remain competitive in global markets, companies are improving their product flow management processes, and the emphasis on streamlining logistics activities in order to reduce time and minimize supply chain costs is crucial in this area. Customers want to receive the ordered goods as soon as possible, so the flexibility of supply chains and their responsiveness to market demand should be as high as possible. The article analyses an integrated planning centre of one of the leading food producers. The planning centre manages the supply chain in the "End2End" model, i.e. from sending the expected demand for components needed for production, through production planning, to the delivery of the final product to the market for the customer. At the same time the centre manages not only the parent company's entities, but also cooperates with partners by integrating individual entities in the supply chain. The proposed improvements will pertain to the broadly understood subject of the flow of goods and information through ERP systems. The area of improvements included management processes in the supply chain of a manufacturing company, in order to improve its internal processes and increase the efficiency of operations.
\end{abstract}

Keywords: Supply Chain, Management Processes, Logistics Centre, End2End, KPI.

\section{$1 \quad$ Introduction}

The economic growth of a given country, and thus its competitiveness, depends on technological progress and implemented innovations. Acceleration of its growth is possible due to the increase in the dynamics of efficiency which is ensured by investments in research and development as well as innovation [6]. High competitiveness and globalization on the markets force companies to create different logistics strategies and at the same time to adapt the chain and structure network to the given area of activity. However, the way logistics networks are built is not always the same, e.g. a different logistics strategy and supply chain management model will be adopted by a local company that produces specialized mechanical components tailored 
to individual customers, and a completely different flow management concept will have a global company that produces fast-moving, unified goods for a large number of first or second order customers. Choosing the right strategy, modelling, integration and supply chain control is one of the challenges companies face.

\subsection{Definitions and Terms}

Different definitions of the supply chain can be found in the available literature, but given that in logistics it is increasingly important to integrate and cooperate with each other and to include a holistic aspect of the product, the best definition seems to be this one: "A supply chain is a network of partners who collectively convert a basic commodity (upstream) into a finished product (downstream) that is valued by endcustomers, and who manage returns at each stage" [3]. The supply chain model for a given product is shown in Figure 1.

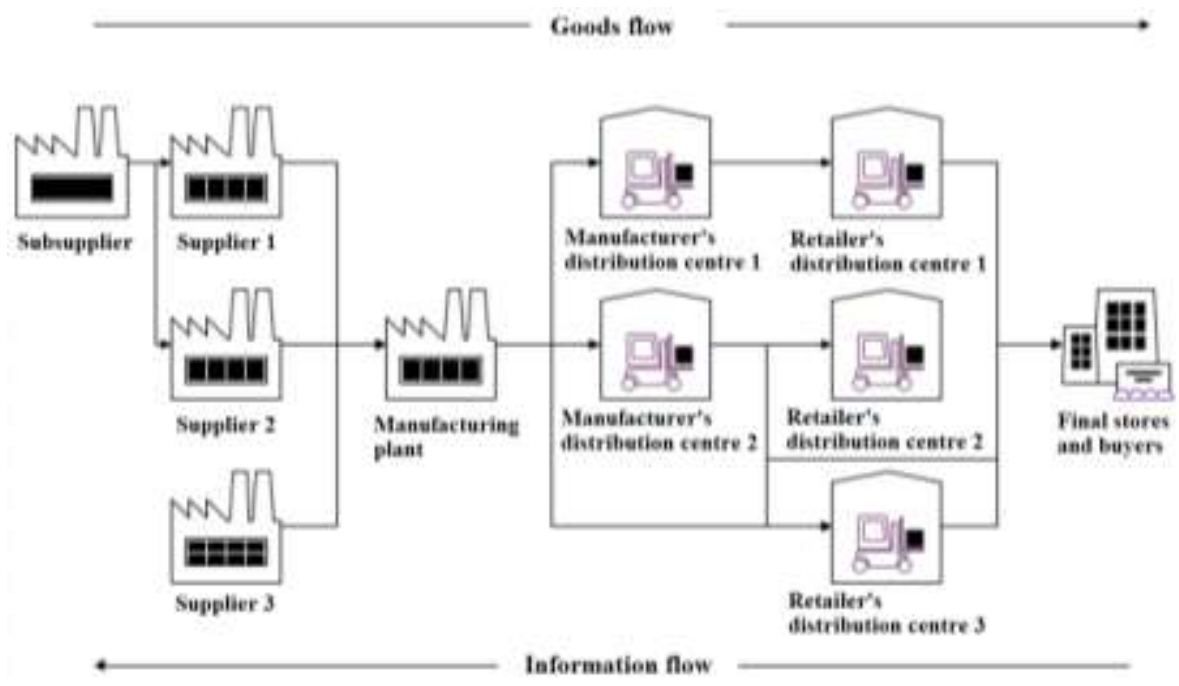

Fig. 1. Supply chain model $[3,9]$.

Figure 1 shows two main streams running from the source of the chain to the final purchaser. These are the flows of goods and information. These are the two basic flows in each logistical process. The supreme goal of logistics is to maintain the continuity of this flow, and both the flow of information and goods should be controlled so that it is not subject to any disruption or downtime.

For better illustration of the integration of the supply chain, Figure 2 shows the model of the supply chain functioning on the basis of a single signal from the purchaser, which triggers an avalanche of information and processes to the entities assigned to it. The signal with a new order is converted for each unit and then the demand information 
is passed down (towards the source of the chain). Then the good flows back to the final recipient.

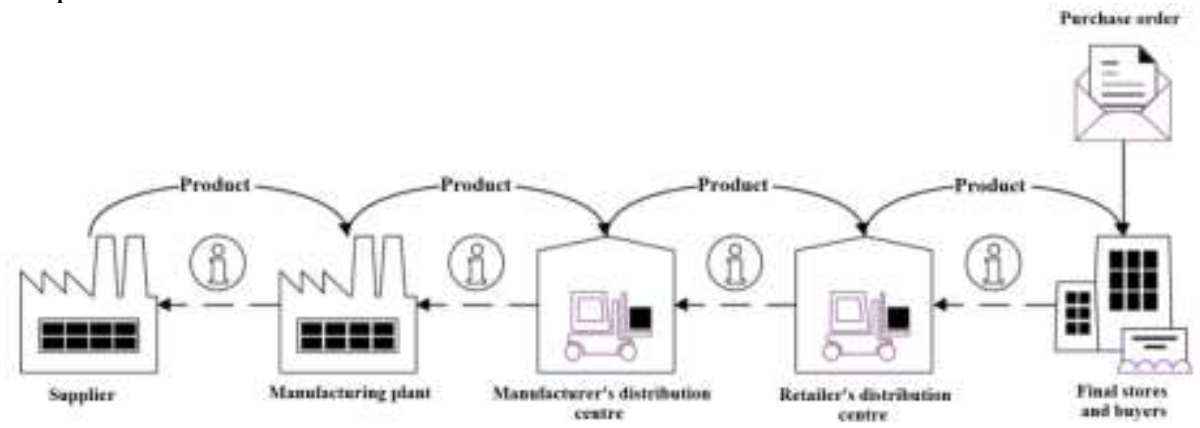

Fig. 2. Diagram of the integrated supply chain $[3,9]$.

This chain is highly integrated above the organisational divisions of individual entities and requires the coupling of individual control systems of cooperating companies. Supply chains are complex systems, dynamic, dispersed and open; is a metastructure [4]. We can distinguish the following approaches to the creation of supply chain strategies [5]:

- evolutionary,

- classic,

- adjustment,

- system.

The main reason for the concept of ECR (Effective Customer Response) was the willingness to combine supply chain management with demand forecasting. The concept was developed as a supply chain management system for companies trading in FMCG (Fast Moving Consumer Goods). The main undertakings on which ECR systems focus include the following tasks:

- category management - the main task of category management is to prevent shortages of goods at the buyer and closer correlation with customers, in order to determine the best possible diversity and offer at the appropriate level of inventory. Additional tasks of category management also include jointly determining the implementation of promotions and new products, removing unprofitable products from the markets or attempting to adjust the prices of products to specific market situations,

- continuous inventory recovery management - in order to manage total inventory more efficiently throughout the supply chain, these activities include material planning, production and distribution through a "pull" mechanism,

- supporting technologies management of - this system is aimed at receiving, processing and making available the most precise information in supply chains, such as: expected demand, consumption and sales, value of product inventories and their realization status. RFID (Radio Frequency Identification) systems are important. 
They allow to monitor the levels of assets on an ongoing basis and obtain a range of information on where a given product is located.

\subsection{Importance of Planning Systems in the Supply Chain}

Supply chain planning systems greatly facilitate decision making and accelerate the monotonous and complex, large-scale calculations that would be required for demand, production or distribution planning. Modern systems, which are based on multi-level planning models, enable full integration of the supply chain and provide complete solutions available to companies, often offering functionality extensions beyond the supply chain management system. Additionally, they perform the function of cloud computing, thanks to which access to them is possible from any place in the world, connected to a common cloud via the Internet [8]. Manufacturing Planning and Control (MPC) systems are designed to meet customer requirements at a higher level by proposing solutions that will streamline logistics processes in the company. In addition, taking into account recent considerations of supply chain theorists, modern systems should not only respond to the current needs of the company, but should also be able to develop in the future in case of technical breakthroughs in supply chain technology or improvement of business processes to a certain level of excellence [11].

The use of such complex systems as ERP (Enterprise Resource Planning) systems for planning in the supply chain requires high accuracy and awareness of the impact of the execution of tasks by employees $[4,10]$. It is important to keep discipline and monitor possible changes in the system on an ongoing basis by persons supervising the supply chain. It is also necessary to know how the individual systems cooperate with each other, therefore the transparency of the system and continuous intensive training for employees are of crucial importance.

\section{Analysis of how to Manage the Supply Chain}

In the surveyed company, logistic measures are used to assess the efficiency of the supply chain due to their reliability. However, in order to use the measures effectively, it is necessary to measure the current state of affairs before introducing improvement measures. Appropriately adjusted measures facilitate decision making and outline appropriate prioritization of tasks for the participant of the measured organisation [7]. A big advantage is the possibility of global application in international organisations, by making them easy to understand, as their systematic character is based on measurable results and numbers and not on general formulas. Key Performance Indicators (KPIs) are measures that assess and measure the extent to which objectives have been achieved. Through the use of KPI measures in an enterprise, we enable the achievement of the objectives of a given entity, without losing the sense of the strategy and mission of the organization [5]. As a result of the KPI analysis it is possible to identify problematic connections in the supply chain [1]. For the supply chain, the following KPIs are mainly distinguished, as presented in Table 1 . 
ERP systems, especially APS modules, can be adjusted to meet KPI targets. With the use of optimization tools, the APS system, using KPI guidelines, can plan production processes for specific resources, taking into account the limitations of individual supply chain actors.

Table 1. Selected KPIs to assess the supply chain, based on [12].

\begin{tabular}{|c|c|c|}
\hline $\begin{array}{l}\text { Category } \\
\text { meter }\end{array}$ & Subcategories & Name meter / indicator \\
\hline \multirow{4}{*}{ Expense } & Expense total & Chain supply total expense \\
\hline & $\begin{array}{l}\text { Main } \\
\text { processes }\end{array}$ & Cost of delivery, production, distribution, supply \\
\hline & $\begin{array}{l}\text { Ancillary } \\
\text { processes }\end{array}$ & $\begin{array}{l}\text { Information flow indicator, transport cost index. Material } \\
\text { flow indicator, order cost indicator, innovative process } \\
\text { indicator }\end{array}$ \\
\hline & Outside costs & Outside environmental costs \\
\hline \multirow{5}{*}{ Time } & Lead time & $\begin{array}{l}\text { Orders, handling processes, manipulation, manufacturing, } \\
\text { production, delivery }\end{array}$ \\
\hline & $\begin{array}{l}\text { Time of } \\
\text { reaction }\end{array}$ & Reactivity, readiness of delivery, speed of information flow \\
\hline & Punctuality & Confidence of delivery \\
\hline & Rhythmicity & Periodicity \\
\hline & Reliability & Indicator of delays, downtime, average delay time \\
\hline \multirow{3}{*}{ Quality } & $\begin{array}{l}\text { Customer } \\
\text { satisfaction }\end{array}$ & $\begin{array}{l}\text { Product availability, complaints, completeness of deliveries, } \\
\text { openness of information, accuracy of communication }\end{array}$ \\
\hline & Infrastructure & $\begin{array}{l}\text { Level of computerization, technical infrastructure, efficiency } \\
\text { environmental }\end{array}$ \\
\hline & Processes & $\begin{array}{l}\text { Processes of adding value, improving the implementation of } \\
\text { processes, planning precision }\end{array}$ \\
\hline \multirow{3}{*}{ Flexibility } & Risk & $\begin{array}{l}\text { Accuracy of forecasts, index of spare production capacity, } \\
\text { risk of process performance, availability of information }\end{array}$ \\
\hline & Service & Flexibility of supplies, availability of deliveries \\
\hline & $\begin{array}{l}\text { Specification } \\
\text { market }\end{array}$ & Seasonality, nature of the product's properties \\
\hline
\end{tabular}

The surveyed company plans and manages the supply chain across Europe for the two categories defined for the organisation. These categories are:

- chewing gum and candies,

- cookies.

The supply chain for each category is managed separately, has separate reporting lines and is unique in terms of business strategy. By creating an integrated planning centre, IT systems are synchronized and uniform in terms of the company's logistics strategy. However, the planning centre does not make the most important decisions regarding the supply chain management strategy on its own. Separate positions and employees 
within the organization are dedicated to building a vision of the supply chain for the entire organization and determining the direction to follow for the entire centre. Supply chain management is not located entirely in a single location, which does not facilitate supply chain management decisions.

Supply Chain Management includes processes related to demand, distribution, manufacturing, components, database and other tasks necessary to synchronize and integrate the supply chain. The weekly cycle starts with the daily development of distribution plans by the system, taking into account market and customer demand and planned procurement. Long-term demands and resource workloads are also automatically planned. The work of a Supply Chain Management Centre planner starts with checking unexecuted orders from the previous week and analysing changes in demand or distribution needs for products. Potential procurement risks are also checked on a daily basis to ensure that information is communicated as quickly as possible and that actions are coordinated to eliminate them. This is followed by adjustments to shortterm production plans and the development of production plans for subcontractors. On the basis of the analysis of resource load, market needs and stock positions, medium term production is planned in order to create the best possible production plan appropriate and tailored to the customer's needs. Then the production plan is transferred to the factory and detailed scheduling of resources. On the basis of the schedule, a detailed, confirmed distribution plan for the products for the distribution centre is created.

While the production plan for the short and medium term is already completed, information is exchanged with the manufacturers in order to transfer the most important priorities for production. At the same time, at the end of the weekly cycle, the process of forecasting the demand for components and sharing the forecast with the deliveries takes place. In parallel, planners carry out work related to database management processes, meetings with supervisors and training courses. The weekly cycle ends with the release of the demand that is analysed and sent by the department to ERP and ASP systems, after which the cycle is repeated from the beginning. During the analysis of the supply chain, the following areas with potential for improvement were identified using the "5 whys" method:

- problems with component management: mainly due to an inappropriate database for component planning and a lack of adequate forecasting for key materials that were supplied by many suppliers,

- problems with the organisation of production: due to the lack of a system solution that would automatically create plans to synchronise production plans for similar product groups,

- management of market coverage: this was due to the lack of an understandable and easy-to-use tool presenting the current stockholding stocks for specific markets on a long-term and short-term basis and to inaccurate plans for the renewal and distribution of stocks in the markets. 


\section{Improvements in Supply Shain Management}

It took more than two years to implement these improvements, mainly in the areas of component and inventory management and production organisation.

\subsection{Improvements Related to Component Management}

Component management in the organization is divided between two positions. The first position is a central planner, whose tasks are more focused on the overall management of components and the creation of system possibilities of ordering components for the factory (e.g. the creation of purchase demand, on the basis of which contracts in the system are created, necessary to create orders to suppliers). The second position is the function of a factory planner, whose main task is to monitor daily material levels in the factory and to ensure that the components needed for production in a given location are available on time. If there are no components necessary to meet the production schedule, the central planner is the first point of contact for the planner at the factory. All material requirements result from the calculation of production plans through BOMs for component requirements in the SAP ECC system.

An analysis carried out at one of the factories showed that the main cause of material shortages are weaknesses in key activities, therefore an attempt was made to correct the processes and the following improvements were proposed:

- carrying out a comprehensive audit of the planning database for all active components in the system,

- the introduction of "best practices" for planners in the factory to increase the efficiency of their work,

- increasing integration with critical suppliers through weekly meetings to monitor potential supply risks from the supplier,

- agree on tariff quota levels for critical raw materials supplied from multiple sources.

\subsection{Improvements in the Organisation of Production}

The company's main focus was on the proper organisation of production, so the area was the most developed in terms of planning. However, due to the supply chain strategy, which was based on maximum responsiveness to customer orders, there was often a need to change the production plan in order to respond to consumer demand, which led to numerous unnecessary rearmaments in the factories. In order to reduce the changeover time in the factory, it was agreed that similar recipes of sweets should be produced as much as possible together, and the SAP APO system in which production is planned should offer these solutions automatically, reducing the number of necessary manual interventions in the system by the planner.

The principle was introduced that the chosen taste will be produced on a weekly basis, allowing for continuous production. Additionally, it was stated that rearmaments will be carried out after the end of the 120-hour production cycle, due to the lower need to involve human resources in the processes of line rearmaments. 


\subsection{Improvements in the Management of Stocks of Finished Products}

A central planner managed the selected product portfolio in many markets, i.e. if he produced an x-product in a specific factory, he was also responsible for the proper coverage of the product in all markets in Europe to which it was sent. Through the philosophy of measuring the complex customer level for a given market or product group within an organisation, there were inventory shortages for less important markets. Adequate risk and inventory management for finished products had to be developed. The tools developed meet the following business needs:

- automatically shows current and planned inventories (for each of the existing products in each market) for a 52-week horizon, adding up the demand for several distribution centres due to the possibility of balancing inventories and orders in a given country,

- the database source can be refreshed on a daily basis and uses only SAP systems,

- collects information on short-term stocks on a daily basis and on a three-week horizon,

- displays the information in a clear, comprehensible and easily transferable way in further communication in the supply chain,

- groups products in order to facilitate portfolio management and prioritise products in order to prioritise the elimination of procurement risks.

The scale of demand coverage has been set as follows: the current minimum number of days of stock coverage is set separately for each product and market:

- over 120 days: to be corrected for exceeding the deadline for the ability to sell a full value product to customers,

- 119-60 days: to be corrected if there are no special business restrictions due to the fact that half of the time limit for selling a full value product to customers is exceeded,

- from 59 to 15 days: acceptable, but with higher numbers of corrective actions,

- from 14 days to 9 days: alarming, necessary correction of supply plans,

- from 8 days to 0 days: for an absolute check, an immediate change of supply plans is needed.

In order to identify supply risks more quickly, a tab identifying all risks has been introduced and the information will be transmitted by the central planner to the generating unit for setting priorities for stock renewals.

\section{$4 \quad$ Selected KPIs}

In order to confirm the effectiveness of the implemented improvements, several KPIs were analysed, and the scope of the analysis was broad enough to confirm the lack of randomness of results. Particular attention was paid to:

- level of customer service, where: 


$$
P O K=\frac{D_{o}}{Z_{o}} \cdot 100 \%
$$

(POK - level of customer service [\%], $D_{\mathrm{o}}$ - number of product packages delivered [packages], $Z_{\mathrm{o}}$ - number of product packages ordered [packages]),

- the share of undelivered product packages due to the purchasing department, where:

$$
P O K N=\frac{z_{n z}}{D_{o}} \cdot 100 \%
$$

(POKN - level of customer service for undelivered packages [\%], $Z_{n z}$ - number of undelivered product packages due to a supply error [packages]),

- conformity of production with the schedule, where:

$$
Z_{Z} H=\frac{\left|L_{Z}-L_{W}\right|}{L_{Z}} \cdot 100 \%
$$

( $Z_{Z} N$ - compliance of production execution with the schedule [\%], $L_{w}$ - quantity of produced product $[\mathrm{kg}], L_{z}$ - quantity of planned product $\left.[\mathrm{kg}]\right)$,

- a stock recovery cycle for finished products in the supply chain, where:

$$
\operatorname{COZ}=P_{1}>P_{2}
$$

( $\mathrm{COZ}$ - stock recovery cycle for finished products [days], $P_{l}$ - previous production of the same product at the factory [days], $P_{2}$ - subsequent production of the same product at the factory [days]),

- the time of stockpile for finished products (the time during which the stock of finished products would run out without renewal of stocks for the selected product), where:

$$
C Z A=\frac{z_{d}}{P_{p}}
$$

(CZA - stock time for finished products [days], $Z_{d}$ - stock available for the product $[\mathrm{kg}], P_{p}$ - expected demand for the product $\left.[\mathrm{kg} / \mathrm{days}]\right)$.

Detailed figures adopted by the above-mentioned indicators and the levels of their development in recent years are a secret of the surveyed company and cannot be presented. However, it can be generally stated that all key indicators confirmed the legitimacy of the introduced improvements in the logistics chain. However, the greatest impact of the implemented improvements was observed in the compliance of the production with the schedule, as shown in Figure 3. 


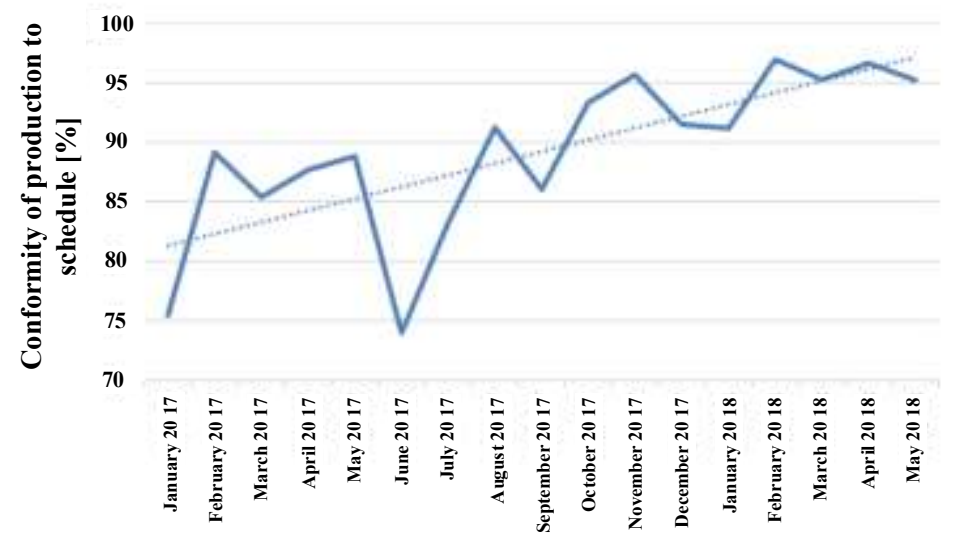

Fig. 3. Evolution of the index of conformity of production execution with the schedule.

The trend line shows a steady increase in the level of this indicator, but in June 2017 we can see the local minimum of the indicator, caused by an unforeseen seasonal surge in demand, caused by the beginning of the hot summer.

\section{Conclusions and Summary}

The implementation of improvements in supply chain management in an integrated planning centre is a multi-stage and long-term task. This article focuses on presenting the idea of building a modern supply chain and the concept of logistics integrating the flow of product and information. Efforts were also made to clarify concepts such as logistics strategy or planning in supply chain management in the broad sense of the term. It also describes the phases of supply chain integration and the strategy of effective customer service in buyer-oriented supply chain modelling. Attention is paid to the role of modern IT systems in planning and management of the organization, as well as their types, structure and areas of operation and functionality in the company. The function and role of the most important from the point of view of flexible supply chain management and IT systems of KPIs in the company are described. The presented example of FMCG supply chain improvement should be treated as a case study for further research and development works.

\section{References}

1. Grzybowska, K.: Reconfiguration to Renovation in a Sustainable Supply Chain. In: Intelligent Systems in Production Engineering and Maintenance - ISPEM 2018, pp. 761770. Springer, Wroclaw (2019).

2. Grzybowska, K., Hoffa-Dąbrowska, P.: Durability of Supply Chains as Non-renewable Systems. In: Burduk, A., Mazurkiewicz, D. (eds.) Intelligent Systems in Production Engineering and Maintenance - ISPEM 2017, pp. 227-237. Springer, Wroclaw (2018). 
3. Harrison, A., Van Hoek, R. I.: Logistics management and strategy: competing through the supply chain. 3rd edn. Prentice Hall Financial Times, Harlow, England (2008).

4. Jacobs, F. R., Berry, W. L., Whybark, D. C., Vollmann, T. E.: Manufacturing planning and control for supply chain management. APICS/CPIM Certification Edition. McGraw-Hill, New York (2011).

5. Jasiulewicz-Kaczmarek, M., Bartkowiak, T.: Improving the performance of a filling line based on simulation. In: IOP Conference Series: Materials Science and Engineering, vol. 145(4), pp. 042024. ModTech 2016, Romania (2016). 10.1088/1757-899X/145/4/042024.

6. Kowalska, A.: Innovation of the Economies of European Union Countries in 2009-2016. In: Proceedings of the 30th International Business Information Management Association Conference (IBIMA), pp. 3514-3523. Madrid, IBIMA (2017).

7. Kowalski, A., Królikowski, S., Szafer, P.: Methods and techniques for evaluating the productivity of production processes in the automotive industry. In: IOP Conference Series: Materials Science and Engineering, vol. 400, pp. 062017. ModTech 2018, Romania (2018). $10.1088 / 1757-899 X / 400 / 6 / 062017$

8. Mell, P., Grance, T.: The NIST Definition of Cloud Computing. National Institute of Standards and Technology, 53(6):50, Gaithersburg (2009).

9. Slack, N., Brandon-Jones, A., Johnston, R.: Operations Management. 7th edn. Pearson Education, Harlow, England (2013).

10. Sobaszek, Ł., Gola, A., Świć, A.: Predictive Scheduling as a Part of Intelligent Job Scheduling System. In: Intelligent Systems in Production Engineering and Maintenance ISPEM 2017, pp. 358-367. Springer, Wroclaw (2018).

11. Trkman, P., Budler, M., Groznik, A.: A business model approach to supply chain management. Supply Chain Management: An International Journal 20(6), 587-602 (2015). 10.1108/SCM-06-2015-0219.

12. Tundys, B., Rzeczycki, A., Zioło, M., Jankowski, J.: Models of an Integrated Performance Measurement System of Intelligent and Sustainable Supply Chains. In: Nguyen, N. T., Attachoo, B., Trawiński, B., Somboonviwat, K. (eds.) Intelligent Information and Database Systems - 6th Asian Conference, ACIIDS 2014, pp. 504-514. ACIIDS 2014, Thailand (2014).

13. Whittington, R.: What is Strategy - and Does it Matter? 2nd edn. Cengage Learning EMEA, London (2001). 